\title{
Guide for Author
}

\section{INDONESIAN JOURNAL OF TROPICAL AND INFECTIOUS DISEASE}

This journal is a peer-reviewed journal established to promote the recognition of emerging and reemerging diseases spesifically in Indonesia, South East Asia, other tropical countries and around the world, and to improve the understanding of factors involved in disease emergence, prevention, and elimination.

The journal is intended for scientists, clinicians and professionals in infectious diseases and related sciences. We welcome contributions from infectious disease specialists in academia, industry, clinical practice, public health and pharmacy, as well as from specialists in economics, social sciences and other disciplines. For information on manuscript categories and suitability of proposed articles see below and visit e-journal. unair.ac.id/index.php/IJTID/ index.

\section{INSTRUCTIONS TO AUTHORS}

\section{ARTICLE STRUCTURE}

Please kindly check our Template.

\section{LANGUAGE}

All manuscripts must be in English, also the table and figure texts.

\section{TITLE PAGE}

Give complete information about each author (i.e., full name, graduete degree(s), affiliation and the name of the institution in which the work was done). Clearly identify the corresponding author and provide that author's mailing address (including phone number, fax number, and email address). Use uppercaser for title except the name of species, only the first letter using uppercase.

\footnotetext{
ABSTRACT

A concise and factual abstract is required. The abstract should state briefly the purpose of the research, the principal results and major conclusions. Abstract should be 250-300 words. It should include objectives and rationale of the study, method used, main findings and significance of findings. It should be accompanied by up to $\mathbf{5}$ Keywords. Abstract should be available in English and Bahasa.

\section{INTRODUCTION}

State the objectives of the work and provide an adequate background, avoiding a detailed literature survey or a summary of the results.
}

\section{MATERIAL AND METHOD}

Provide sufficient detail to allow the work to be reproduced. Methods already published should be indicated by a reference: Only relevant modifications should be described.

\section{RESULT AND DISCUSSION}

Results should be clear and concise Results presented in the tables and figures should not be repeated unnecessarily in the text. Result should be presented without interpretation and followed by the discussion section which should provide an interpretation of the results in relation to findings of other investigators. Discussion should explore the significance of the results of the work, not repeat them. A combined Results and Discussion section is often appropriate. Avoid extensive citations and discussion of published literature.

\section{CONCLUSION}

Conclusions should be stated clearly. The main conclusions/summary of the study may be presented in a short Conclusions section, which may stand alone or form a subsection of Results and Discussion section. Conclusion section is for Research Report/Original Article and Summary is for Literature Review/Review Article.

\section{ACKNOWLEDGEMENT}

All acknowledgements including financial support should be mentioned under this heading. List here those individuals who provided help during the research (e.g., providing language help, writing assistance or proof reading the article, etc.).

\section{REFERENCES}

Please ensure that every reference cited in the text is also present in the reference list (and vice versa). Minimum 15 references for research report/original article and 30 references for review. References wrote on Vancouver (superscript) Style. In the Vancouver Style, citations within the text of the essay/paper are identified by Arabic numbers in superscript. This applies to references in text, tables and figures.

The Vancouver (Superscript) System assigns a number to each reference as it is cited. A number must be used even if the author(s) is named in the sentence/text. e.g. Smith ${ }^{10}$ has argued that...

The original number assigned to the reference is reused each time the reference is cited in the text, regardless of its previous position in the text. When multiple 
references are cited at a given place in the text, use a hyphen to join the first and last numbers that are inclusive. Use commas (without spaces) to separate non-inclusive numbers in a multiple citation e.g. $2,3,4,5,7,10$ is abbreviated to..

The placement of citation numbers within text should be carefully considered e.g. a particular reference may be relevant to only part of a sentence. As a general rule, reference numbers should be placed outside full stops and commas and inside colons and semicolons, however, this may vary according to the requirements of a particular journal.

Examples - There have been efforts to replace mouse inoculation testing with in vitro tests, such as enzyme linked Immunosorbent assays ${ }^{57,60}$ or polymerase chain reaction ${ }^{20-22}$ but these remain experimental. Moir and Jessel maintain "that the sexes are interchangeable".

\section{TABLES}

Tables should be embedded in page. Provide footnotes and other information (e.g., source/copyright data, explanation of boldface). Tables should be no wider than $17 \mathrm{~cm}$. Condence or divide larger tables. Please submit tables as editable text and not as images. Number tables consecutively in accordance with their appearance in the text and place any table notes below the table body. Be sparing in the use of tables and ensure that the data presented in them do not duplicate results described elsewhere in the article. Please avoid using vertical rules and shading in table cells.

\section{FIGURES}

Provide figures embedded in page. Figures should be drawn professionally. Photographs should be sharp (contrast). Provide footnotes and other information (e.g., source/copyright data, explanation of boldface) in figure legend. Submit image files (e.g., electromicrograph) without text content as high-resolution (300 dpi/ ppi minimum) TIFF or JPG files. Ensure that each illustration has a caption. Supply captions separately, not attached to the figure. A caption should comprise a brief title (not on the figure itself) and a description of the illustration. Keep text in the illustrations themselves to a minimum but explain all symbols and abbreviations used.

\section{EQUATIONS}

Equations (refer with: Eq. 1, Eq. 2,..) should be indented $5 \mathrm{~mm}(0.2$ "). There should be one line of space above the equation and one line of space below it before the text continues. The equations have to be numbered sequentially, and the number put in parentheses at the right-hand edge of the text. Equations should be punctuated as if they were an ordinary part of the text. Punctuation appears after the equation but before the equation number. The use of Microsoft Equation is allowed.

$c^{2}=a^{2}+b^{2}$.

\section{PLAGIARISM CHECK}

The manuscript has not been published previously (partly or in full), unless the new work concerns an expansion of previous work (please provide transparency on the re-use of material to avoid the hint of text-recycling ("self-plagiarism"). Please kindly tell us if you already use plagiarism check (Turnitin, etc.).

The writing process of article is suggested to use reference manager program (Mendeley, etc.)

\section{ARTICLE PROCESSING CHARGE}

Due to the necessity of increasing the IJTID quality, starting from January $1^{\text {st }} 2018$, there would be ratified article processing charge for publication in Indonesian Journal of Tropical Infectious Disease, IDR 1 Million or USD 75. Payment applies after the manuscript is accepted in the editing process.

\section{TYPES OF ARTICLES}

\section{RESEARCH REPORT/ORIGINAL ARTICLE}

Articles should be under 3000 to 4000 words and should include references. Use of subheadings in the main body of the text in recommended. Photographs and illustrations are encouraged. Provide a short abstract (250 - 300 words). These are detailed studies reporting original research and are classified as primary literature. The Original Research format is suitable for many different types of studies. It includes full Introduction (background), Methods, Results, and interpretation of findings in Discussion sections.

\section{CASE REPORT/CASE STUDIES}

These articles report specific instances of interesting phenomena. A goal of Case Studies is to make other researchers aware of the possibility that a specific phenomenon might occur. Case reports/studies present the details of real patient cases from medical or clinical practice. The cases presented are usually those that contribute significantly to the existing knowledge on the field. The study is expected to discuss the signs, symptoms, diagnosis, and treatment of a disease. These are considered as primary literature and usually have a word count similar to that of an original article. Clinical case studies require a lot of practical experience.

\section{LITERATURE REVIEW/REVIEW ARTICLES}

Review articles give an overview of existing literature in a field, often identifying specific problems or issues and analysing information from available published work on the topic with a balanced perspective. Review articles are usually long, with the maximum word limit being 3000-6000 or even more, depending on the topic. 


\section{COPYRIGHT TRANSFER AGREEMENT}

The author who submit the manuscript must understand that if accepted for publication, the copyright of the article belongs to Indonesian Journal of Tropical and Infectious Disease and Institute Tropical Disease Universitas Airlangga as the publisher of the journal.

Copyright includes the exclusive right to reproduce and deliver articles in all forms and media, including reprints, photographs, microfilm and any other similar reproduction, as well as translation. The author has the right to the following:

1. Duplicate all or part of the published material for use by the author himself as a classroom instruction or verbal presentation material in various forums;

2. Reusing part or all of the material as a compilation material for the author's work;

3. Make copies of published material to be distributed within the institute where the author works.

Indonesian Journal of Tropical and Infectious Disease and Institute Tropical Disease Universitas Airlangga and Editor make every effort to ensure that no false or misleading data, opinions or statements are published in this journal. The contents of articles published on Indonesian Journal of Tropical and Infectious Disease are the sole and exclusive responsibility of each author.

Authors must complete and sign the Copyright Transfer of Agreement Form available at https://goo.gl/XdbW3R. The form is sent as a supplementary file when submitting articles. 


\section{COPYRIGHT TRANSFER AGREEMENT}

I, the undersigned, on behalf of all authors, hereby declare that the following article is an original work of the author and has never been published published in any medium (proceedings, journals and books).

Manuscript Title

Authors $: 1$.

2.

3.

Affiliation

If this article is accepted for publication in the issue number in Indonesian Journal of Tropical and Infectious Disease (IJTID), then I hereby submit all copyright to Indonesian Journal of Tropical and Infectious Disease and Institute Tropical Disease Universitas Airlangga as a journal publisher.

Copyright includes the exclusive right to reproduce and provide articles in all forms and media, including reprints, photographs, microfilms and any other similar reproduction, as well as translation. The author still has the right to the following:

1. Duplicate all or part of the published material for use by the author himself as a classroom instruction or verbal presentation material in various forums;

2. Reusing part or all of the material as a compilation material for further writers' writings;

3. Make copies of published material to be distributed within the institute where the author works.

I am responsible for the entire contents of the submitted article. I would like to make this statement in order to be used as intended. I agree that this transfer of rights also applies to all copies made in connection with the submission of this article and I will also inform this agreement to other authors.

Date

Author's Name

Main authors signature: (using handwriting)

Note: If this article is not received then this letter is declared no longer valid.

The form has been completed and signed scanned and saved in PDF format and must be submitted as supplementary files when sending articles. If difficulties, Authors may send to ijtid@itd.unair.ac.id 